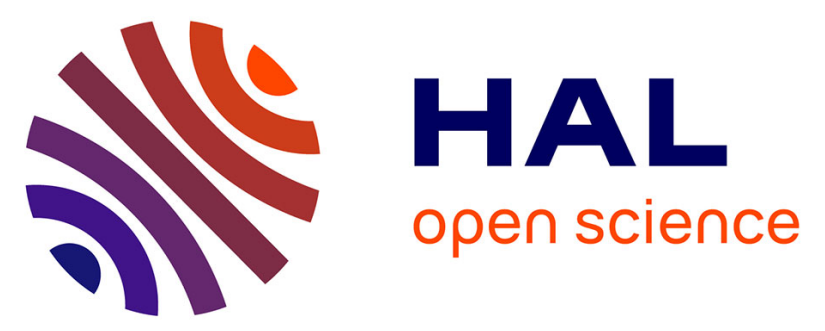

\title{
Comparison between fresh and fixed human biopsies using spectral and lifetime measurements: Fluorescence analysis using one and two photon excitations
}

Fanny Poulon, Marc Zanello, Ali Ibrahim, Amira J. Zaylaa, Pascale Varlet, Bertrand Devaux, Darine Abi Haidar

\section{To cite this version:}

Fanny Poulon, Marc Zanello, Ali Ibrahim, Amira J. Zaylaa, Pascale Varlet, et al.. Comparison between fresh and fixed human biopsies using spectral and lifetime measurements: Fluorescence analysis using one and two photon excitations. 2015 International Conference on Advances in Biomedical Engineering (ICABME), Sep 2015, Beirut, Lebanon. 10.1109/ICABME.2015.7323242 . inserm-01238642

\section{HAL Id: inserm-01238642 https://www.hal.inserm.fr/inserm-01238642}

Submitted on 18 Dec 2015

HAL is a multi-disciplinary open access archive for the deposit and dissemination of scientific research documents, whether they are published or not. The documents may come from teaching and research institutions in France or abroad, or from public or private research centers.
L'archive ouverte pluridisciplinaire HAL, est destinée au dépôt et à la diffusion de documents scientifiques de niveau recherche, publiés ou non, émanant des établissements d'enseignement et de recherche français ou étrangers, des laboratoires publics ou privés. 


\title{
Comparison Between Fresh and Fixed Human Biopsies Using Spectral and Lifetime Measurements: Fluorescence Analysis Using One and Two Photon Excitations
}

\author{
F. Poulon ${ }^{* 1}$, M. Zanello ${ }^{* 1,2}$, A. Ibrahim ${ }^{* 1}$, A. J. Zaylaa ${ }^{3}$, P. Varlet ${ }^{4}$, B. Devaux ${ }^{2}$ and D. Abi Haidar ${ }^{1,5}$ \\ ${ }^{1}$ IMNC Laboratory, UMR 8165-CNRS, Orsay, France \\ 2 Department of Neurosurgery, Sainte Anne Hospital, France \\ ${ }^{3}$ Department of Electrical and Computer Engineering, American University of Beirut, Lebanon \\ ${ }^{4}$ Department of Neuropathology, Sainte Anne Hospital, France \\ ${ }^{5}$ University of Paris 7-Paris Diderot, F-75012 Paris, France
}

\begin{abstract}
The purpose of this study is to make a comparison between the fluorescence emissions of fresh extracted human biopsies and fixed human biopsies, in order to evaluate the impact of fixation on autofluoresence signal. Our group is developing an endo-microscope to image brain tissues in-vivo, however to date, in order to validate our technology the easiest type of samples we can access are fixed samples. However, the fixation is still challenging. For that, we aim through this study to determine whether we should pursue to work on fixed samples or we should shift to work on fresh biopsies. Data were collected on spectroscopic, lifetime measurement and fluorescence imaging set-ups with visible and two-photon excitations wavelengths. Five fresh and five fixed samples are involved in the experiment. Endogenous fluorescence of fixed biopsies were calculated. Experimental results reveal that at $405 \mathrm{~nm}$ and $810 \mathrm{~nm}$, the fresh samples have an intensity of fluorescence two times higher than that of fixed samples. However, for each fluorophore and each excitation wavelength, the lifetime for fresh samples is shorter than that for fixed samples. Still, further studies and investigations involving the comparison between different samples are required to strengthen our findings.
\end{abstract}

Index Terms-Spectroscopic analysis, lifetime domain measurements, human biopsies, fixed tissues, fresh tissues.

\section{INTRODUCTION}

A major cause of variation in the endogenous fluorescence tissue emission, between fresh and fixed tissue, is related to the tissue fixation, and to a lesser degree, to the tissue processing. The most important problem is the inadequate tissue dehydration prior to paraffin embedding [1]. Researchers have encountered changes in autofluorescence induced by fixation, and evaluated the changes. Thereby, the use of ex-vivo fixed samples as adequate control samples is not adopted. In this study, one and two photons spectroscopy and fluorescence lifetime signals were recorded sequentially from the collected specimen on two set-ups: the first one situated at the Sainte Anne Hospital (Paris, France) and the second one available at PIMPA platform, at the IMNC Laboratory (Orsay, France). The purpose of this study is to compare multimodal optical analysis made on a fresh and fixed samples, in order to determine the variations in autofluorescence induced by the fixation process.

\section{Materials And Methods}

\section{A. Samples}

Five Fresh biopsies were first analyzed with the fibered spectroscopic and lifetime set-up at the Sainte Anne Hospital, then an accredited professional transporter brought tissues to PIMPA platform. Two photon Fluorescence (TPF), Second Harmonic Generation (SHG), spectral signal and Fluorescence Lifetime Imaging Microscopy (FLIM) signal were recorded sequentially from the collected biopsies on a classical benchtop 2PEF microscope. Correlations between point-to-point optical indexes, imaging abnormalities and pathological examination of biopsy samples were performed. An illustration of the multimodal analysis on human biopsies is illustrated in Fig. 1.

After optical analysis on fresh samples, all tissue specimens were fixed according to Sainte Anne Hospital Neuropathology Department's protocol (formalin 4\%) [2], studied after an overnight fixation on the PIMPA platform and were transported back to Sainte Anne Hospital. Fixed biopsies have benefited from a second analysis on the optical set-up and undergone pathological analysis.

\section{B. Set-ups}

1) Spectroscopic and lifetime measurements: An optical set-up was settled at the Sainte-Anne Hospital in order to measure the autofluorescence of human brain samples as close as possible to the in-vivo conditions. It was a bi-fiber setup, one fiber to excite the fluorophore at $345 \mathrm{~nm}$ and $405 \mathrm{~nm}$ and the other one to collect the intensity of fluorescence and send it to the spectrometer or to the Photo Multiplier Tube for lifetime measurement analysis. This set-up has been previously published [3]. 


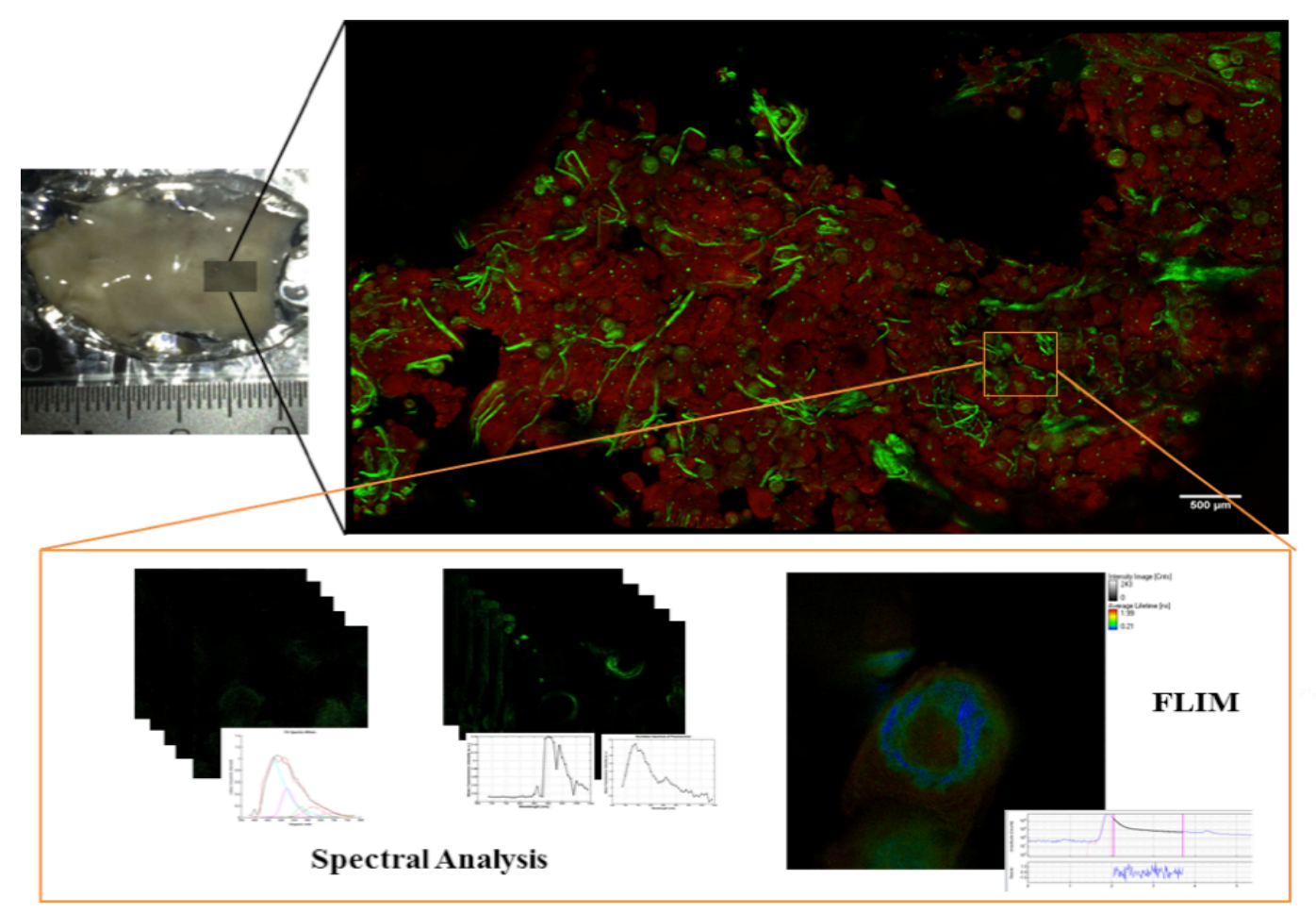

Fig. 1: Our set-up and different imaging modalities.

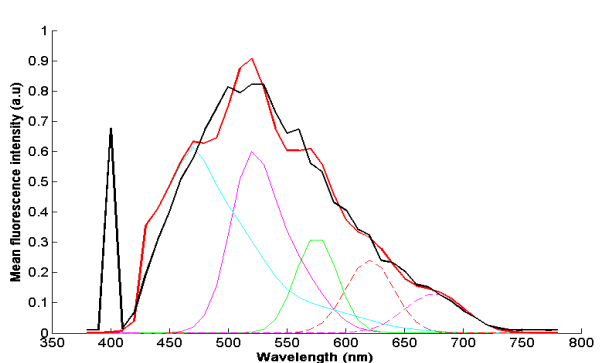

(a)

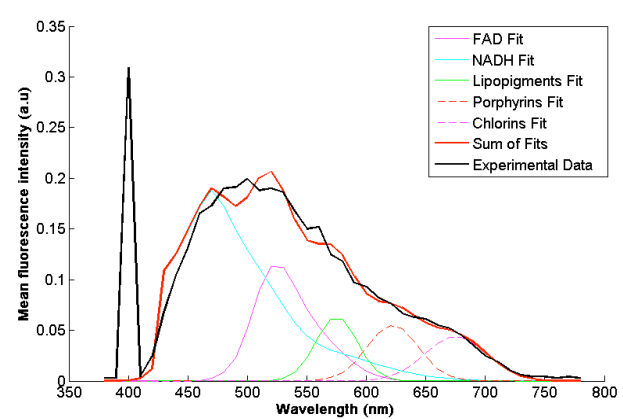

(d)

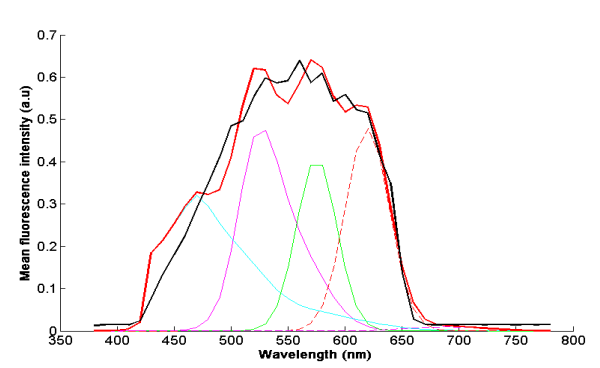

(b)

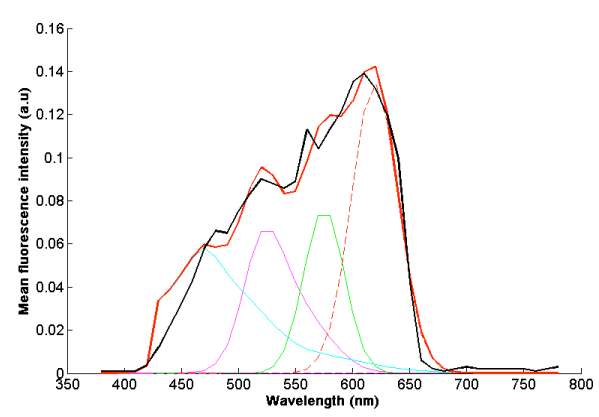

(e)

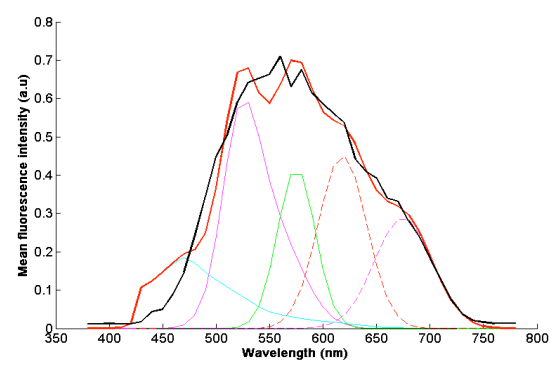

(c)

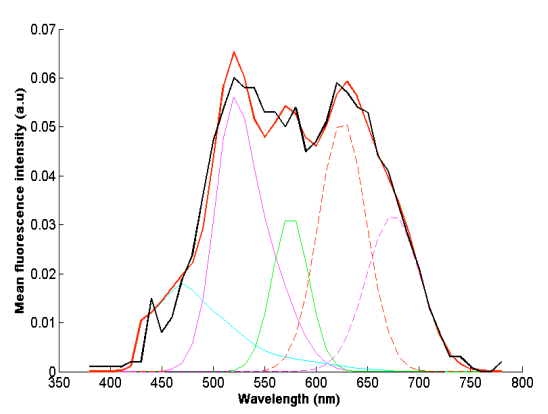

(f)

Fig. 2: Representation of the mean fluorescence intensity versus the wavelengths. (a,b,c) fits on the fresh sample. (d,e,f) fits on the fixed sample at $405 \mathrm{~nm}(\mathrm{a}, \mathrm{d}), 810 \mathrm{~nm}(\mathrm{~b}, \mathrm{e})$ and $890 \mathrm{~nm}(\mathrm{c}, \mathrm{f})$. 


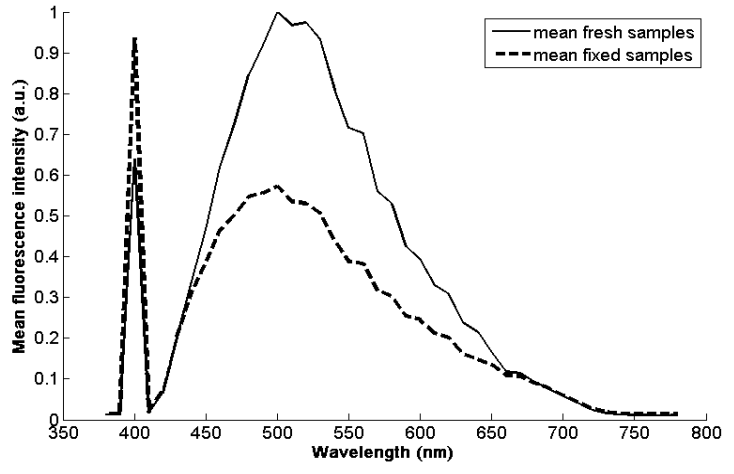

(a)

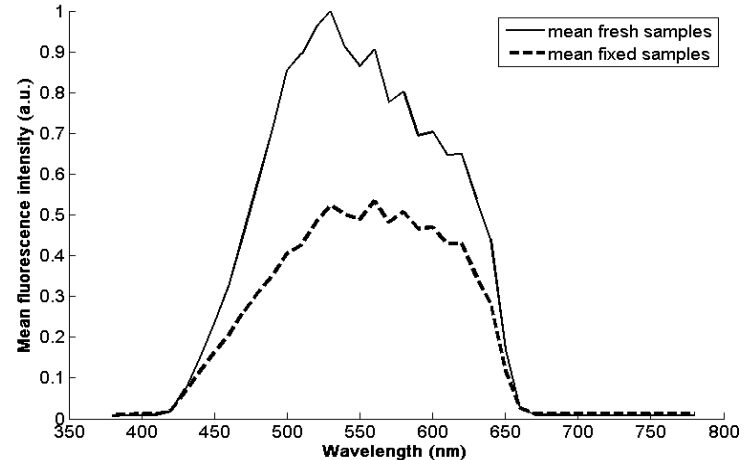

(b)

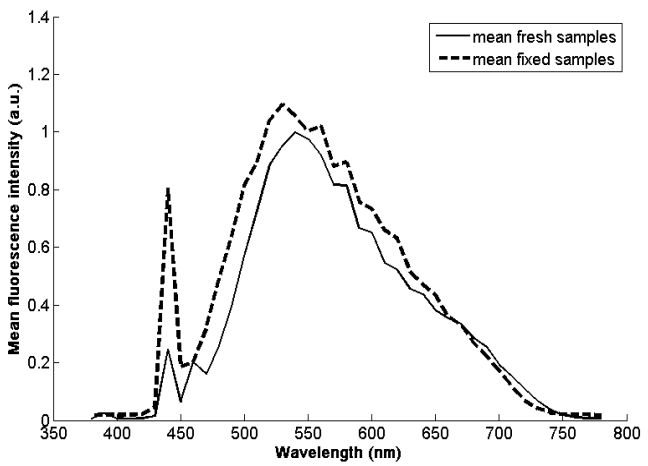

(c)

Fig. 3: Mean on five fresh and fixed samples at (Top) $405 \mathrm{~nm}$, (Middle) $810 \mathrm{~nm}$ and (Bottom) $890 \mathrm{~nm}$.

2) Multimodal wide-field excitation imaging: one and twophotons: At the IMNC laboratory, samples were imaged using a Leica TCS SP8-FLIM microscope on PIMPA platform. The confocal spectral detection, using $405 \mathrm{~nm}$ excitation wavelength, was used to make an emission spectrum. A Mai Tai DeepSee Ti: Sapphire oscillator with automated dispersion compensation was used to produce non-linear excitations. The Mai Tai DeepSee laser has over $2.4 \mathrm{~W}$ of average power and $350 \mathrm{~nm}(690-1040 \mathrm{~nm})$ in usable tuning range. Respectively, 810 and $890 \mathrm{~nm}$ excitation wavelengths are used to perform multimodal imaging of fluorescence, SHG, spectral signal and FLIM.

\section{RESULTS}

\section{A. Two photon spectral analysis}

Using visible and Infra-Red (IR) excitations, we were able to excite five endogenous fluorophore: reduced Nicotinamide adenine dinucleotide (NADH), Flavins (FAD), Lipopigments, Porphyrins and Chlorins. We could also measure SHG at 445 $\mathrm{nm}$ using $890 \mathrm{~nm}$ excitation wavelength. We developed a Matlab script to fit these different fluorophores [3], we will use it here to fit the spectra and observe the change in the mean intensity of fluorescence between fresh and fixed samples.
Fig. 2, a and d showcase the variation of the intensity of fluorescence as a function of the wavelengths using FAD, NADH, Lipopigments, porphyrins, chlorins, sum of fits and experimental data at $405 \mathrm{~nm}$, for fresh and fixed tissues, respectively. In the former figure the maximum mean intensity is obtained using NADH for both fresh and fixed tissues.

In fresh tissues, the flavins contribute to the the increase of $25 \%$ in the mean fluorescence compared to the fixed tissues. Moreover, Lipopigments contribute to $10 \%$ the increase in the mean fluorescence compared to fixed tissues. In Fig. 2, $\mathrm{b}$ and e, there is a significant shift in the mean intensity of fluorescence; in the (b) fresh samples, FAD is the dominant fluorophore, whereas, in the (e) fixed samples Porphyrin is the dominant one.

At $890 \mathrm{~nm}$, Fig. $2 \mathrm{c}$ and $\mathrm{f}$ showcase that in fresh samples, FAD fit contributes to the highest intensity of fluorescence for both fresh and fixed tissues. Moreover, porphyrins contribute to $75 \%$ the maximum intensity of fluorescence for the fixed samples.

In a fixed biopsy both FAD and porphyrins give a peak at the maximum intensity of the fluorescence signal. Moreover, using SHG, the peak at $445 \mathrm{~nm}$, there is a $20 \%$ increase in the intensity from fresh to fixed samples.

Fig. 3 showcases the mean spectrum at 405, 810 and 890 
$\mathrm{nm}$, respectively, for fresh and fixed samples. At $405 \mathrm{~nm}$ and $810 \mathrm{~nm}$, the fresh samples have an intensity of fluorescence two times higher than that of fixed samples, however, at 890 $\mathrm{nm}$ there was no change in the mean of the intensity of fluorescence between the fixed and fresh samples.

\section{B. One photon spectral and lifetime analysis}

At $375 \mathrm{~nm}$ and $405 \mathrm{~nm}$ we measured the fluorescence lifetime on a PMT linked to a PicoQuant system. In front of the PMT, a 5 band-pass filters were placed to select each fluorophore. The measurements have been done on the 5 samples in the fresh and fixed conditions. Table I reports the mean results. For each fluorophore and each excitation wavelength, the lifetime for fresh samples is shorter than that for fixed samples.

\section{DISCUSSION AND CONCLUSION}

Studies have shown that the endogenous fluorescence of human tissues decreases with the time afterwhich the biopsy is taken out [4], then the endogenous fluorescence stabilizes at a value lower than that in in-vivo measurements. The lower endogenous fluorescence value in fixed tissues could be due to the delay between the removal of the biopsy and the fixation of the sample.

TABLE I: Fluorescence Lifetime.

\begin{tabular}{|c|c|c|c|}
\hline & & Fresh Samples & Fixed Samples \\
\hline $375 \mathrm{~nm}$ & NADH & $3.44 \pm 0.35$ & $4.30 \pm 0.26$ \\
\hline & FAD & $3.66 \pm 0.08$ & $3.89 \pm 0.03$ \\
\hline $405 \mathrm{~nm}$ & NADH & $3.09 \pm 0.32$ & $3.57 \pm 0.11$ \\
\hline & FAD & $2.78 \pm 0.22$ & $3.46 \pm 0.20$ \\
\hline & Lipopigments & $4.21 \pm 0.09$ & $9.05 \pm 0.30$ \\
\hline & Prophyrins & $1.80 \pm 0.13$ & $2.37 \pm 0.06$ \\
\hline & Chlorins & $1.59 \pm 0.12$ & $1.89 \pm 0.04$ \\
\hline
\end{tabular}

The impact of fixation on lifetime measurement is not yet a popular subject, and our literature review found only few existing studies. Ganguly et al. and Joosen et al. published work tackling this issue [5], [6]. They investigated the effect of cells fixation on the fluorescence lifetime. In both studies, the fixation by the formaldehyde has reduced the fluorescence lifetime. The difference between these results and our work could be explained by the use of different samples: several previous work involved proteins in fixed cells, while, we worked on the endogenous fluorescence of fixed biopsies. The lifetime value of each molecule and of the surrounding environment is specific [7] . Probably, the formaldehyde does not have the same effect on proteins in single cells compared to biopsies of human brain tumor.

Results reveal that at $405 \mathrm{~nm}$ and $810 \mathrm{~nm}$, the fresh samples have an intensity of fluorescence two times higher than that of fixed samples. However, for each fluorophore and each excitation wavelength, the lifetime for fresh samples is shorter than that for fixed samples.
Still, further studies and investigations involving the comparison between different media and samples are required to strengthen the former conclusion.

\section{ACKNOWLEDGEMENTS}

This work is supported by a Plan Cancer with Physicancer program grant MEVO, a Dfi instrumental program grant from CNRS.

\section{REFERENCES}

[1] M. Werner, A. Chott, A. Fabiano, and H. Battifora, "Effect of formalin tissue fixation and processing on immunohistochemistry," The American Journal of Surgical Pathology, vol. 24, no. 7, pp. 1016-1019, 2000.

[2] C. H. Fox, F. B. Johnson, J. Whiting, and P. P. Roller, "Formaldehyde fixation," Journal of Histochemistry and Cytochemistry, vol. 33, no. 8, pp. 845-853, 1985. [Online]. Available: http://decapoda.nhm.org/pdfs/ 1505/1505.pdf

[3] D. A. Haidar, B. Leh, M. Zanello, and R. Siebert, "Spectral and lifetime domain measurements of rat brain tumors," Biomedical Optics Express, vol. 6, no. 4, pp. 1219-1233, 2015.

[4] A. C. Croce, S. Fiorani, D. Locatelli, R. Nano, M. Ceroni, F. Tancioni, E. Giombelli, E. Benericetti, and G. Bottiroli, "Diagnostic Potential of Autofluorescence for an Assisted Intraoperative Delineation of Glioblastoma Resection Margins $\backslash \mathrm{P}$, , Photochemistry and Photobiology, vol. 77, no. 3, pp. 309-318, 2003.

[5] S. Ganguly, A. H. Clayton, and A. Chattopadhyay, "Fixation alters fluorescence lifetime and anisotropy of cells expressing EYFP-tagged serotonin 1a receptor," Biochemical and Biophysical Research Communications, vol. 405, no. 2, pp. 234-237, 2011.

[6] L. Joosen, M. Hink, T. Gadella, and J. Goedhart, "Effect of fixation procedures on the fluorescence lifetimes of Aequorea victoria derived fluorescent proteins," Journal of Microscopy, vol. 256, no. 3, pp. 166176, 2014.

[7] Y. Sun, N. Hatami, M. Yee, J. Phipps, D. S. Elson, F. Gorin, R. J. Schrot, and L. Marcu, "Fluorescence lifetime imaging microscopy for brain tumor image-guided surgery," Journal of Biomedical Optics, vol. 15, no. 5, pp. 056 022-056 022, 2010. 